\title{
Comparative Study of the West African Continental, Coastal, and Marine Atmospheric Profiles during the Summer of 2006
}

\author{
Ibrahima Kalil Kante, ${ }^{1,2}$ Daouda Badiane, ${ }^{1}$ Saïdou Moustapha Sall, ${ }^{1}$ Abdoulaye Deme, ${ }^{1}$ \\ and Arona Diedhiou ${ }^{3}$ \\ ${ }^{1}$ Laboratoire de Physique de l'Atmosphère et de l'Océan Siméon Fongang, Ecole Supérieure Polytechnique, Université Cheikh \\ Anta Diop Dakar-Sénégal, BP: 5085, Dakar, Senegal \\ ${ }^{2}$ Direction Nationale de la Météorologie de Guinée-Conakry, BP: 566 Rep., Guinea \\ ${ }^{3}$ IRD/LTHE, BP 53, 38041 Grenoble Cedex 9, France
}

Correspondence should be addressed to Daouda Badiane, daouda.badiane@ucad.edu.sn

Received 9 July 2011; Revised 16 December 2011; Accepted 24 January 2012

Academic Editor: Gregory S. Jenkins

Copyright ( $\odot 2012$ Ibrahima Kalil Kante et al. This is an open access article distributed under the Creative Commons Attribution License, which permits unrestricted use, distribution, and reproduction in any medium, provided the original work is properly cited.

\begin{abstract}
We used sounding data of the Multidisciplinary Analysis of the African Monsoon experience in summer 2006 at continental and coastal sites of West Africa, respectively, to analyze the vertical profiles of relative humidity, temperature, dew point, and speed and wind direction for the JJAS rainy period. The vertical gradient method is applied to the profiles of some thermodynamic parameters estimated from sounding data to do a comparative study of the structure and thermal properties, moisture, and static stability of the atmospheric boundary layer of inland, coastal, and marine sites to show consistent differences related to geographic factors. In vertical profiles of relative humidity, the intensity is higher in Dakar than in Niamey particularly in the core of the season. There are dry intrusions in the low levels at the beginning and end of the season in Dakar, which do not exist in Niamey. The mixing layer on the continent during the day can reach a height greater than $1100 \mathrm{~m}$, and the inversion layer height can exceed $1700 \mathrm{~m}$. Therefore, the maximum thickness of the boundary layer is observed on the continent during the day, while at night the marine boundary layer is the thickest. The diurnal evolution shows that the mixing layer thickness decreases during the night over the continent but increases at the coast and at sea. In the night at the continental site there is a division of the mixing layer with a consistent residual mixing layer. Continental boundary layer is more unstable during the day, while at night it is the marine boundary layer that is more unstable than the coastal and inland ones.
\end{abstract}

\section{Introduction}

The term boundary layer was first introduced in the literature by Prandtl and Lustig [1]. Since then, many authors such as Turner [2], Monin [3], Zeman [4] and more, recently, Cushman-Roisin and Beckers [5] have studied the detailed description. The atmospheric boundary layer $(\mathrm{ABL})$ has been variously defined, but it is commonly recognized as the lower part of the atmosphere, which is strongly influenced by the presence of the earth's surface and responds to surface forcing with a timescale of about one hour or less. The ABL is the place where many processes, such as turbulence, friction, dispersion, energy dissipation, and wind shear occur. These processes are poorly parameterized in atmospheric models.
Several ABL studies have focused on the turbulence but also on the mixing process triggered by significant warming or cooling [6]. Within the ABL, the transport of various quantities (heat, pollution, moisture, momentum, etc.) is mainly influenced horizontally by the wind and vertically by the turbulence. The importance of the entrainment process of the air at the top of the boundary layer over the continent has been studied by Betts et al. [7] by analyzing the variations of potential temperature $\left(\theta_{e}\right)$.

However, many gaps exist in understanding the $\mathrm{ABL}$, particularly in West Africa where the ABL is poorly studied due to lack of data. Indeed Johnson [8] studied the GATE (GARP Atlantic Tropical Experiment) data to find a link between the thickness of the mixing layer and deep 
convection and inferred a simple model of the boundary layer associated with the passage of mesoscale precipitation systems with the help GATE experimental data. Recently, data obtained during the African Monsoon Multidisciplinary Analysis (AMMA) experience allowed more specific studies of ABL in West Africa [9-11].

In this paper, we analyze and compare relative humidity, dew point temperature, speed and wind direction vertical profiles, and atmospheric boundary layers of continental (Niamey), coastal (Dakar), and marine (Sal) sites located in West Africa. We use data from the special observations phase called SOP3 (Special Observing Period 3) of summer 2006 during the AMMA experience, when there were many sounding observations at various sites in West Africa $[12,13]$. The objective is to analyze the seasonal evolution over the period June, July, August, and September (JJAS) and the profiles of some characteristic parameters of the boundary layer such as relative humidity, dew point temperature, wind speed, and wind direction in order to make a finer characterization and understand the variability. It is also an issue if there are consistent differences in the ABL related to several factors such as the continentality, the proximity of the ocean, the state of static stability, and mesoscale weather systems. In addition, we attempt to identify the characteristic parameters that determine the ABL structure in our study area and highlight any differences between the structures and thermodynamic properties of the ABL of, respectively, continental, coastal and coastal sites. Finally, we seek to determine the diurnal evolution of the structure and thermodynamic properties of these different types of ABL.

\section{Data and Methodology}

2.1. Data. We used sounding data from the AMMA SOP3 experience in summer 2006 in West Africa. We have made a first step for a diagnosis of sounding data to select those that seem appropriate for our study. The data availability is illustrated by Figures 1(a), 1(b), 1(c), and 1(d) for the continental, coastal, and marine sites.

2.1.1. Availability and Consistency of Data by Category of Site and by Month. Figure 1(a) shows that continental (Bamako and Niamey) and coastal (Dakar) sites have more than $80 \%$ of data available at 0000 UTC and 1200 UTC in June, while those marine (Sal, Praia) have no information for that month. Figure 1(b) shows that continental (Abidjan, Agadez, Bamako, Niamey) and coastal (Dakar) sites exceed $80 \%$ of data available for 0000 UTC and 1200 UTC in July. While among the marine sites, only Sal has few data at 1200 UTC. We dismissed the month of July. Figure 1(c) shows that for August, the continental (Agadez, Niamey, and Bamako) and coastal (Abidjan and Dakar) sites exceed $80 \%$ of data availability at 0000 UTC and 1200 UTC.

Sounding data are quite not available for the marine sites (Sal, Praia) at 0000 UTC and 1200 UTC (about 19\%). Because Sal has limited data at 1200 UTC, we did not use the month of July. Finally in Figure 1(d), we find that continental (Bamako and Niamey) and coastal (Abidjan and Dakar) sites have more than $80 \%$ data available at 0000 UTC and at 1200 UTC.

Following the diagnosis of availability and data consistency, we use the Niamey (inland) and Dakar (coastal) sites for the first part concerning the study of vertical profiles of the troposphere on the entire seasonal period. For the second part of our study focusing on the boundary layer based on sounding data case studies, we consider in addition to these two first sites and Sal (marine).

2.1.2. Case Studies. Three case studies were selected according to the criterion that the 1200 UTC sounding data have the maximum values of CAPE during the month of August at each of all three sites (Table 1). To study the diurnal evolution of the ABL, we take the sounding at $0000 \mathrm{UTC}$ of the night when the next or previous sounding data exist. This is the case for Niamey and Dakar sites. For Sal, we take the first sounding data available at 0000 UTC four days later. Thus the three case studies consist of Niamey, Dakar, and Sal sounding data at 1200 UTC according to the instability criterion on, respectively, 26, 17, and 19 August 2006. The sounding data at 000 UTC used are those from 25, 18, and 23 August 2006, respectively, in Niamey, Dakar, and Sal sites. August is the time of year when the convective activities are more intensive in our study area [14]. Figure 2 shows Meteosat- 8 water vapor channel images corresponding to the case study dates. Figures 2(a) and 2(b) show convective systems on or near Niamey site. While Figures 2(c) and 2(d) indicate no deep convection systems over or near Dakar site. Finally, Figures 2(e) and 2(f) show the presence at the Sal site of the Saharan Air Layer (SAL), which is a mass of dry air.

2.2. Methodology. We present the different methods used to process the sounding data and deduce the vertical thermodynamic profiles, structures, thermal, and moisture properties of boundary layers in order to analyze and inter-compare them.

2.2.1. Hovmoêller Diagrams. We plotted relative humidity, dew point temperature, speed and wind direction hovmoêller diagrams (altitude-time) of 1200 UTC and 0000 UTC sounding data. The time period in hovmoêller diagrams is June, July, August, and September, denoted in the following JJAS. This diagram is used to analyze the seasonal thermodynamic vertical profiles of the troposphere of continental (Niamey) and coastal (Dakar) sites.

\subsubsection{Determination of the ABL Structure and Tempera- ture and Moisture Properties. Many authors have proposed methods for determining the structure of the atmospheric boundary layer [15-17]. These methods allow identifying the ABL structural elements as sublayers that are the surface layer, mixing layer, and the capping inversion generally above the mixing layer. These ABL structural elements are described extensively in the literature [17]. Each of these elements is associated with characteristic profiles of key parameters and physical variables. The key parameters to be chosen depend on the nature of the data and applications}




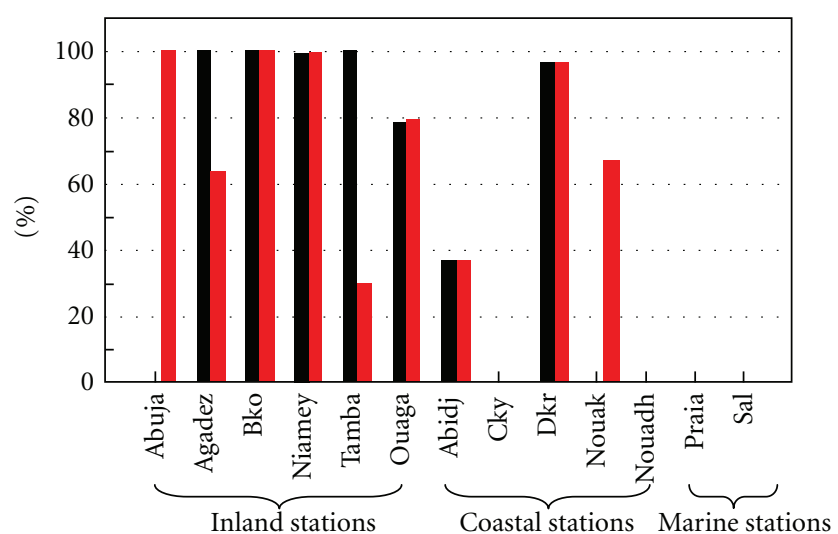

- Data at $00 \mathrm{~h}$

- Data at $12 \mathrm{~h}$

(a)

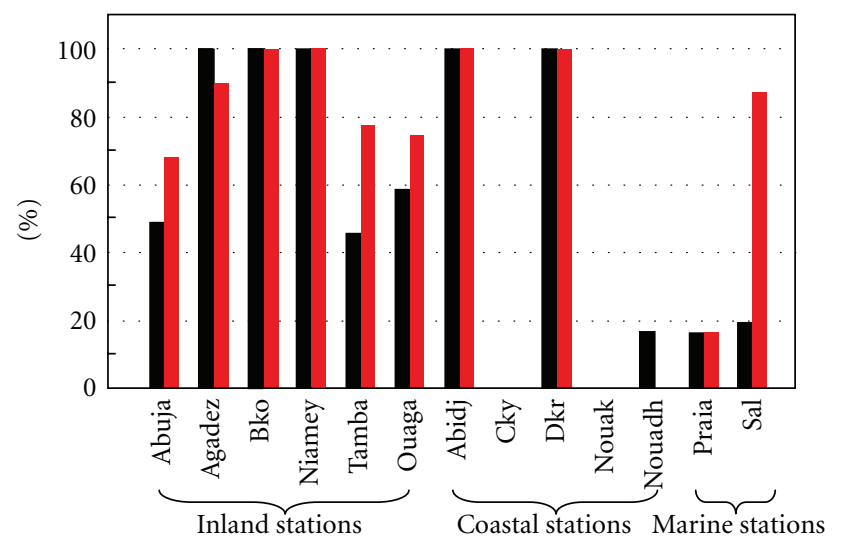

- Data at $00 \mathrm{~h}$

- Data at $12 \mathrm{~h}$

(c)

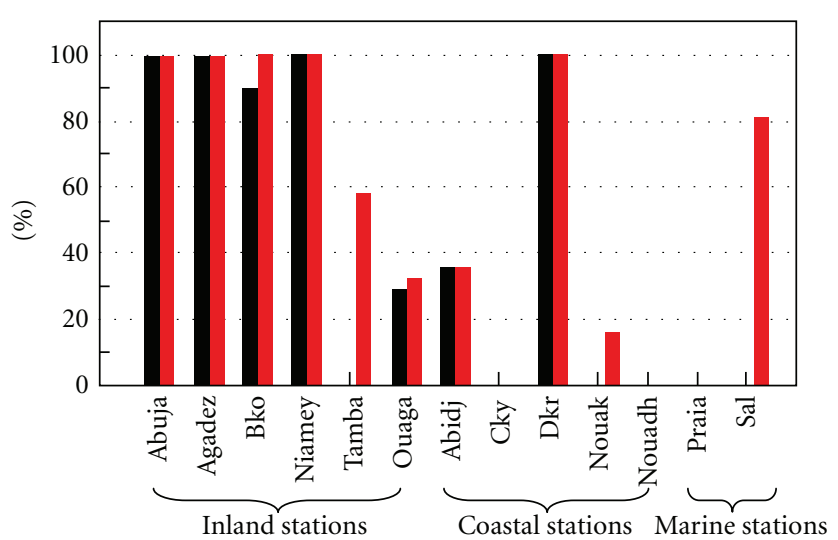

- Data at $00 \mathrm{~h}$

- Data at $12 \mathrm{~h}$

(b)

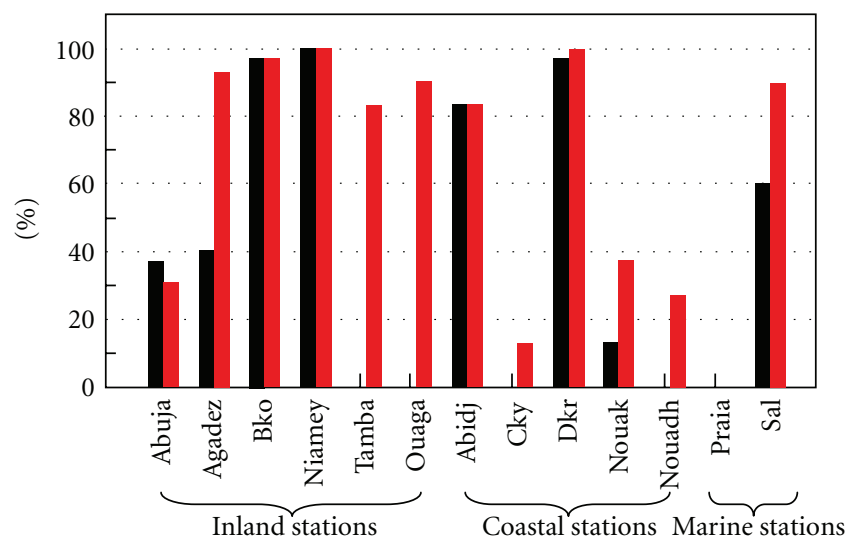

- Data at $00 \mathrm{~h}$

- Data at $12 \mathrm{~h}$

(d)

Figure 1: Data availability for the different categories of sites for the months of June (a), July (b), August (c), September (d) of 2006.

TABLE 1: CAPE maximum values for the selected case studies.

\begin{tabular}{|c|c|c|c|c|}
\hline \multirow{2}{*}{ Stations } & \multicolumn{4}{|c|}{ CAPE $\left(\mathrm{JKg}^{-1}\right)$} \\
\hline & \multicolumn{2}{|c|}{ Maximum at $12 \mathrm{~h}$} & \multicolumn{2}{|c|}{ Maximum at $00 \mathrm{~h}$} \\
\hline Niamey & $08 / 26 / 2006$ & 3789 & $08 / 25 / 2006$ & 3721 \\
\hline Dakar & $08 / 17 / 2006$ & 4473 & $08 / 18 / 2006$ & 3589 \\
\hline Sal & $08 / 19 / 2006$ & 2196 & $08 / 23 / 2006$ & 2394 \\
\hline
\end{tabular}

used in the study of the boundary layer $[16,18]$. In this study, we used sounding data and apply the vertical gradient methods of some thermodynamic parameters such as potential temperature $\theta$, virtual potential temperature $\theta_{v}$, equivalent potential temperature $\theta_{e}$, specific humidity $q$, mixing ratio $r$, and saturation mixing ratio $r_{w}$. Figure 3 shows virtual temperature $\theta_{v}$, potential temperature $\theta$, equivalent potential temperature $\theta_{e}$, and mixing ratio saturating $r_{w}$ profiles deducted from sounding data at 1200 UTC case studies of the three sites. Examination of these profiles reveals that those of virtual potential temperature $\theta_{v}$ and saturating mixing ration $r_{w}$ are quite similar. With the profile of potential temperature $\theta$, we can easily identify the structural elements of the boundary layer. In the following part, we explain how we apply the gradients method on the profiles of the various parameters used to determine the ABL structure and temperature and moisture properties.

(1) ABL Characteristic Parameters. Simplified diagrams of the vertical profile of potential temperature $\theta$ have been proposed to model the structure of the boundary layer [15, $19,20]$.

It is an ABL conceptual representation and shows the structural elements and their descriptive parameters. The mixing layer has been variously defined $[16,21]$, but we 


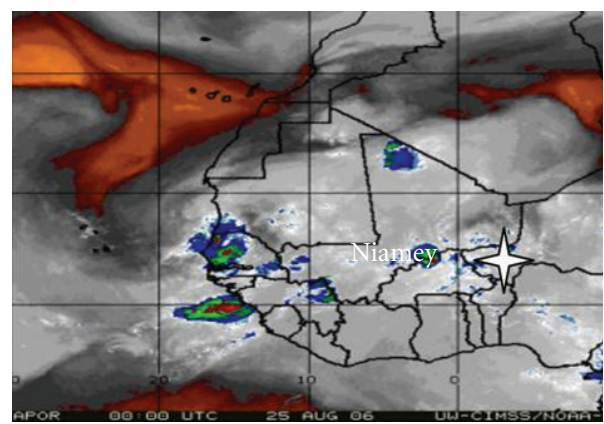

(a) $08 / 25 / 06$ at 0000 UTC

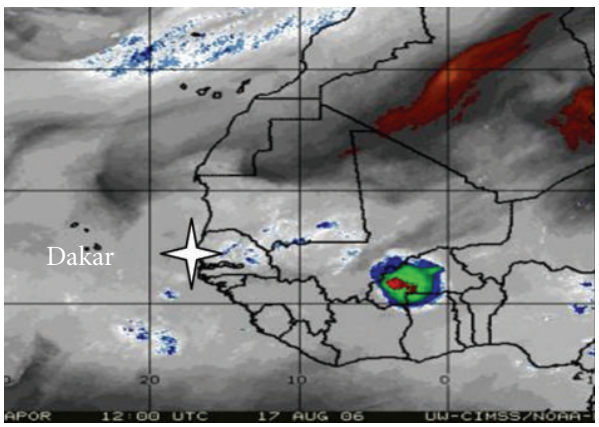

(c) $08 / 17 / 06$ at 1200 UTC

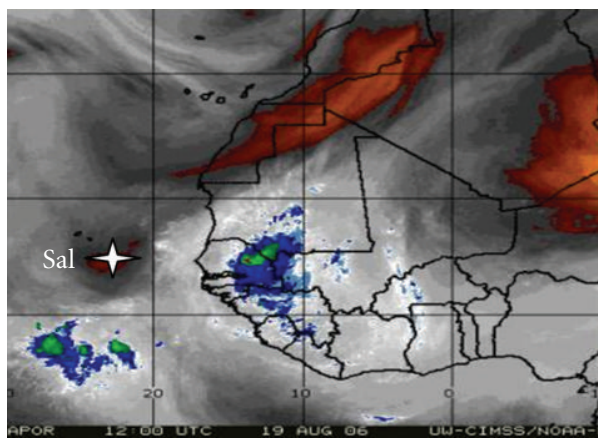

(e) $08 / 19 / 06$ at 1200 UTC

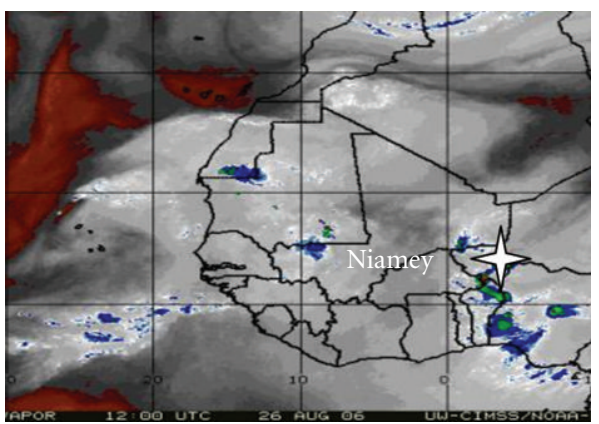

(b) $08 / 26 / 06$ at 1200 UTC

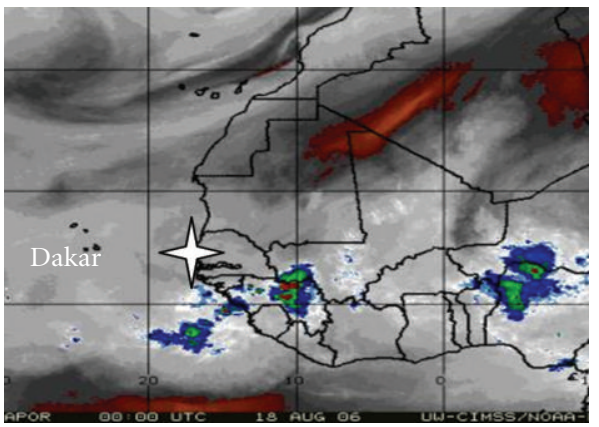

(d) $08 / 18 / 06$ at 0000 UTC

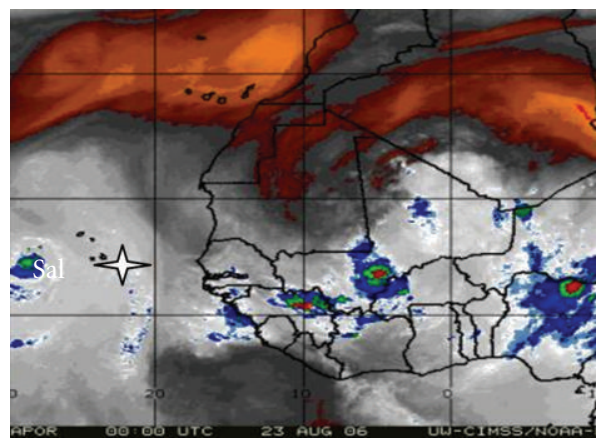

(f) $08 / 19 / 06$ at 1200 UTC

FIGURE 2: Images Meteosat-8-Upper Level Water Vapor in Niamey (a) and (b), Dakar (c) and (d), and Sal (e) and(f) 00 UTC and 12 UTC. The orange color represents the very dry air associated with airborne dust. The colors green, blue, and red represent areas of deep convection. (source: uw-CIMSS/NOAA-HR).

consider it here as a part of the boundary layer in which the vertical gradient of potential temperature $\theta$ is very low or even zero. In other words, in the mixing layer, the value of $\theta$ remains almost constant with height. The part surmounting the mixing layer where potential temperature $\theta$ increases rapidly and presents a sharp discontinuity is the capping inversion layer. Above the inversion layer, we find the free atmosphere that is the upper limit of the boundary layer. The third structural element of the boundary layer is the surface layer, which is located in the immediate vicinity of the ground.

The parameters used to characterize the structural elements of the boundary layer are heights $h_{s}, h_{0}, h_{1}$, the thickness $\Delta h$, and the thermal quantities such as $\theta_{m}, \theta_{00}$, $\Delta \theta, \gamma$ (Figure 4). The heights $h, h_{0}, h_{1}$ represent, respectively, those of the surface layer, of the mixing layer, and of the inversion layer. $\Delta h$ is the capping inversion layer thickness. The thermal parameters $\theta_{m}, \theta_{00}, \Delta \theta, \gamma$ correspond, respectively, to the potential temperature of the mixed layer, the potential temperature in the free atmosphere interpolated at altitude $z=0$, the amplitude of the potential temperature in the capping inversion layer, and the asymptotic gradient of potential temperature in the free atmosphere [18].

In a real sounding, in general the profile of potential temperature $\theta$ may deviate from that of the conceptual model in Figure 4 as a function, among others, of the degree of convective activity, the amount of moisture in the lower atmosphere [17], and of large and medium scales weather conditions [8]. Here, we apply the gradients method to potential temperature $\theta$, which seems more efficient for our individual sounding data to determine the structure of the boundary layer (Figure 3 ). 


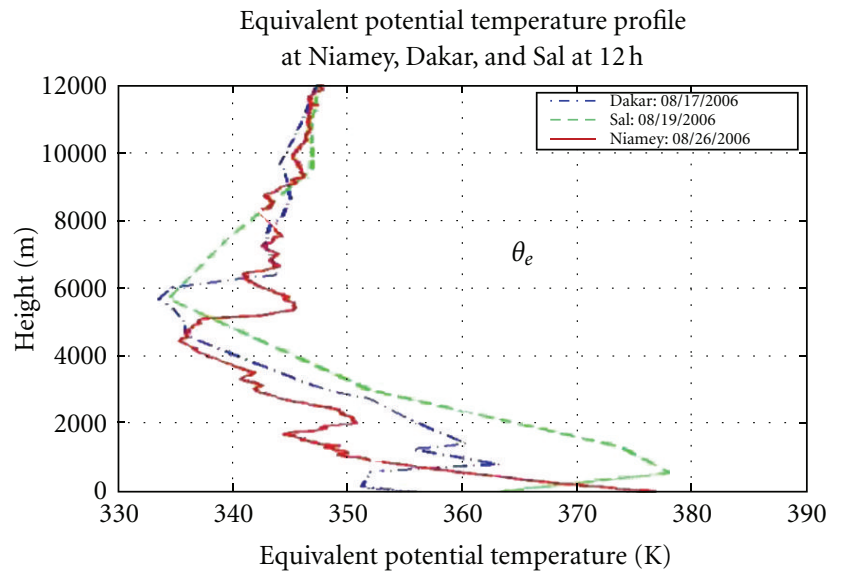

(a)

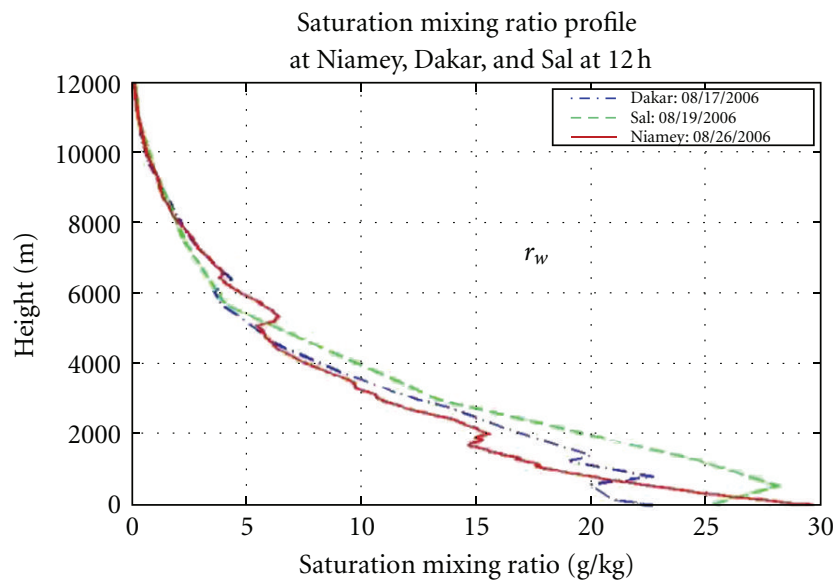

(c)

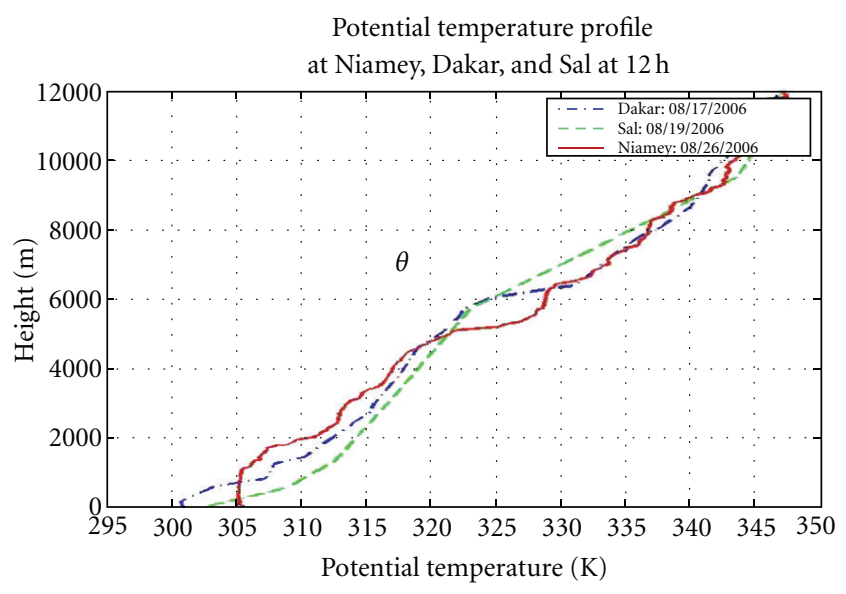

(b)

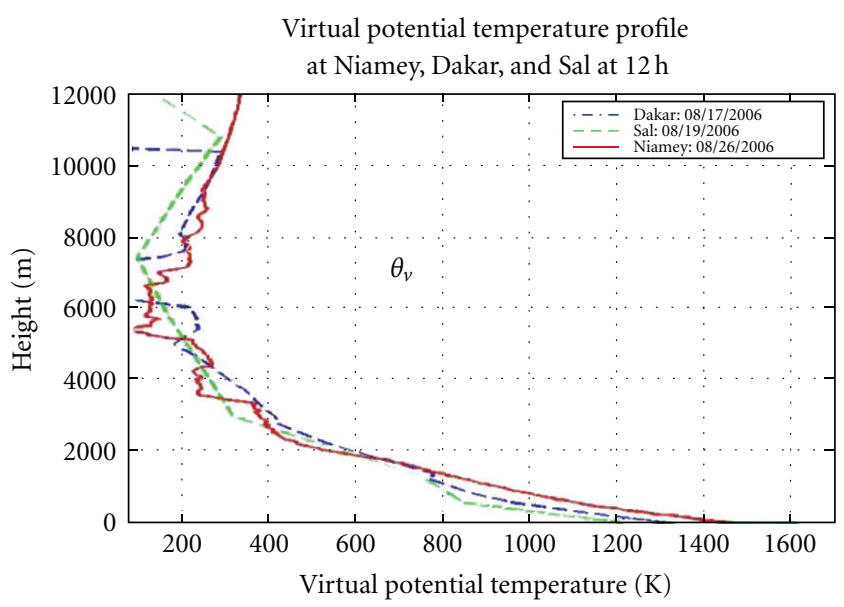

(d)

FIGURE 3: Profiles of virtual potential temperature $\theta_{v}$, potential temperature $\theta$, equivalent potential temperature $\theta_{e}$, and saturating mixing ratio $r_{w}$ of the three case studies selected.

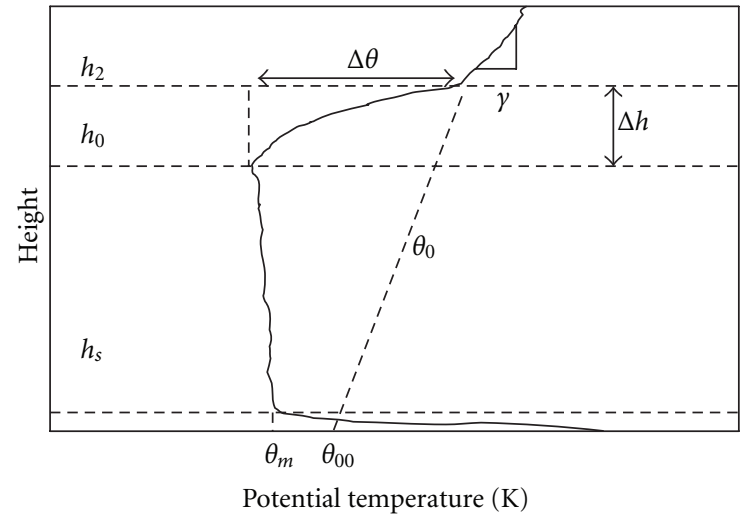

FIgURE 4: ABL Conceptual representation of the structure with the profile of potential temperature $\theta$ (Adapted from [18]).

2.2.3. Static Stability. Unlike some authors who have used it to determine the height of the boundary layer $[17,21]$, we use the gradient of equivalent potential temperature $\theta_{e}$ here to determine the static stability of each layer. Thus, when within an atmospheric layer, the variation of the parameter $\theta_{e}$ is monotone, we determine the static stability as follows.

(i) If $\theta_{e}$ decreases with height in a layer, the later is unstable.

(ii) If $\theta_{e}$ remains almost constant with height in a layer, the later is neutral.

(iii) If $\theta_{e}$ increases with height in a layer, the later is stable.

2.2.4. ABL Thermal and Moisture Properties. It is also the profile of equivalent potential temperature $\theta_{e}$ that we used to determine the thermal properties of the ABL different structural elements. The profile of the mixing ratio $r$ is used for determining the ABL moisture properties.

\section{Results and Discussion}

The results presented concern the continental (Niamey), coastal (Dakar), and marine (Sal) sites. This is due to the quality and availability of data from these sites during 


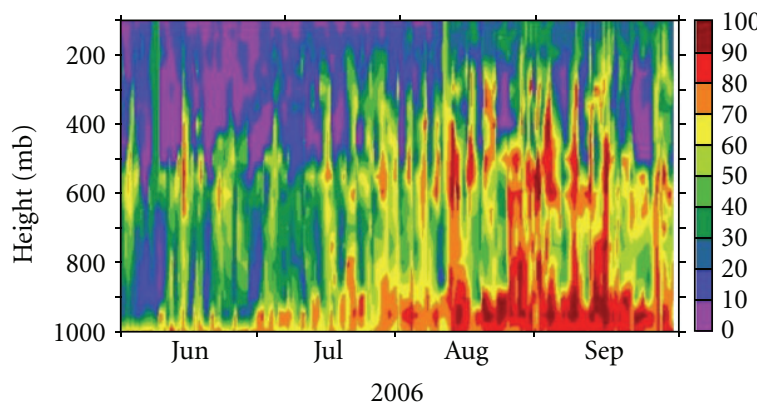

Time evolution of the vertical profile: the mean daily relative humidity during JJAS at Dakar in 2006

(a) Dakar

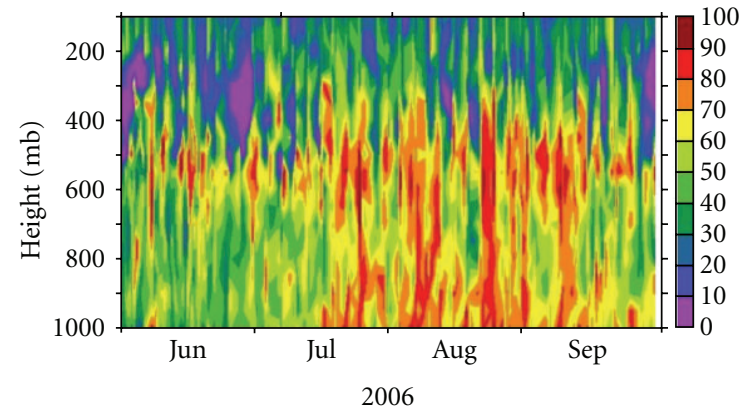

Time evolution of the vertical profile: the mean daily relative humidity during JJAS at Niamey in 2006

(b) Niamey

FIgURE 5: Daily humidity profiles in Dakar and Niamey at 0000 UTC and 1200 UTC of 2006 JJAS.

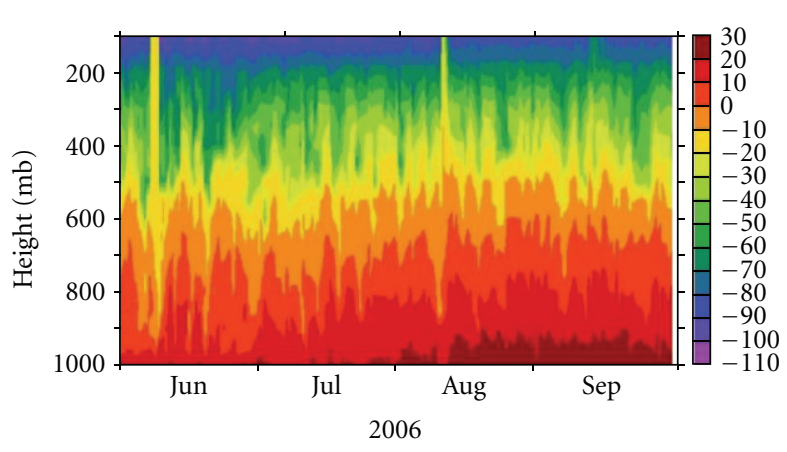

Time evolution of the vertical profile: the mean daily dew point temperature during JJAS at Dakar in 2006

(a) Dakar

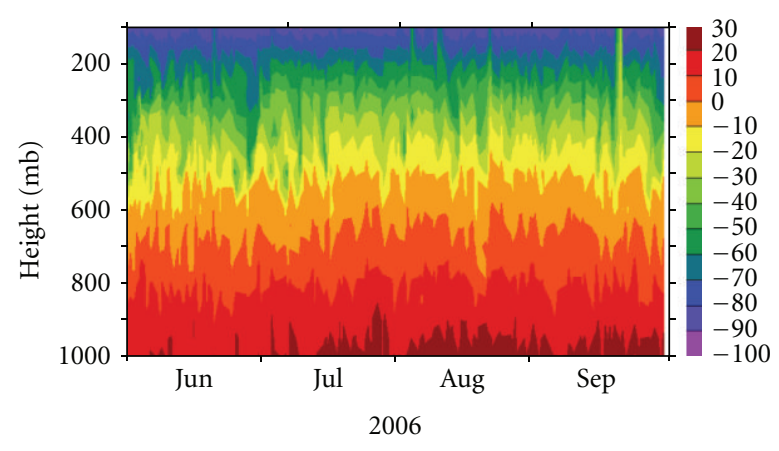

Time evolution of the vertical profile: the mean daily dew point temperature during JJAS at Niamey in 2006

(b) Niamey

Figure 6: Dew point temperature profiles in Dakar and Niamey at 0000 UTC and 1200 UTC of JJAS 2006.

AMMA SOP3 experience. The hovmoêller outputs (Altitudetime) of the relative humidity, dew point temperature, and wind speed and wind direction parameters for the period JJAS are plotted with data from Dakar and Niamey sites. The profiles of potential temperature $\theta$, of equivalent potential temperature $\theta_{e}$, and of mixing ratio $r$ were analyzed for the case studies. The case studies are the most unstable atmospheres in August in Dakar, Niamey and Sal after a systematic analysis of the CAPE and CIN values during JJAS period. The profiles allow us to compare the structures of continental, coastal, and marine boundary layers.

\subsection{Profiles of Moisture at Coastal (Dakar) and Continental} (Niamey) Sites in JJAS 2006. There is increased moisture at Dakar site ranging from $70 \%$ to $80 \%$ from June, at the low levels (Figure 5). In early summer (June), dry air intrusions are observed both in the low and mid levels, which limit the development of deep convection. In the core of the rainy season (August and September), the humidity is intense even at the mid levels $(400 \mathrm{hPa})$. However, there are dry air intrusions during the last week of September at the mid levels.

Figure 5(b) indicates that Niamey site compared to Dakar site has a low relative humidity (50\% and $70 \%$ ) at low levels and comparable or greater humidity intensity than Dakar site at the mid levels. In addition, there is no dry air intrusion in early summer at the low levels; the dry air intrusions are confined only to mid levels.

The low levels at Dakar site are relatively wetter than those to Niamey, probably because of the proximity of the ocean. Dry air intrusions are observed in the low levels in the early season in Dakar in contrast to Niamey. From July, the moisture content is more homogeneous with height at Niamey site than at Dakar site, that is to say that ABL is more developed in Niamey than in Dakar (Figure 5).

\subsection{Profiles of Dew Point Temperature Td at Coastal (Dakar)} and Continental (Niamey) Sites in JJAS Period. Figure 6(a) shows that at the low levels, the dew point temperature (Td) is low at the start of the season JJAS, between 10 and $20^{\circ} \mathrm{C}$, and it increases during the season. It reaches values between $20^{\circ} \mathrm{C}$ and $30^{\circ} \mathrm{C}$ during the core of the wet season (August and September) at the low levels. This corresponds to a strong moistening of the ABL at the coast. However, there was in early season (June), low dew point temperature at the low levels, indicating dry air intrusions observed in the moisture profiles (Figures 5(a) and 5(b)). 


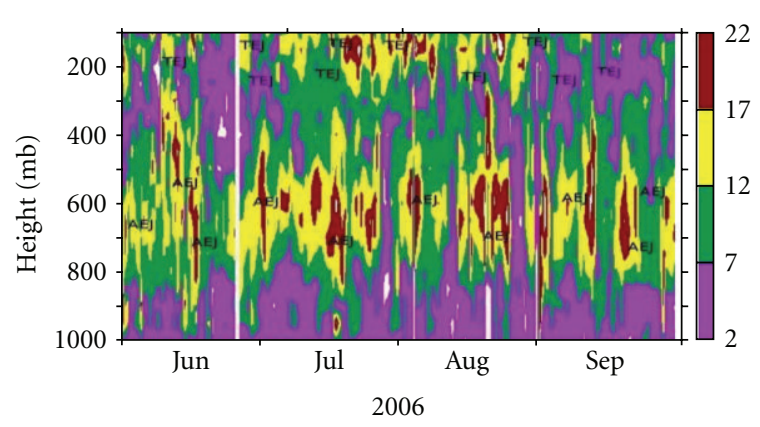

Time evolution of the vertical profile: the mean daily wind speed during JJAS at Dakar in 2006

(a) Dakar

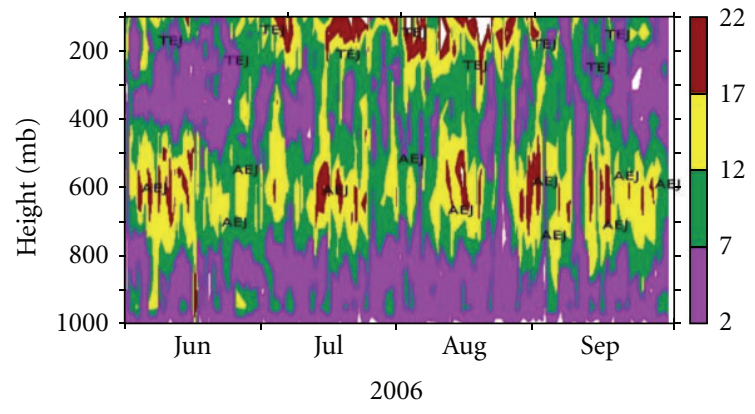

Time evolution of the vertical profile: the mean daily wind speed during JJAS at Niamey in 2006

(b) Niamey

FIgURE 7: Wind speed profiles in Dakar and Niamey at 0000 UTC and 1200 UTC during JJAS 2006.

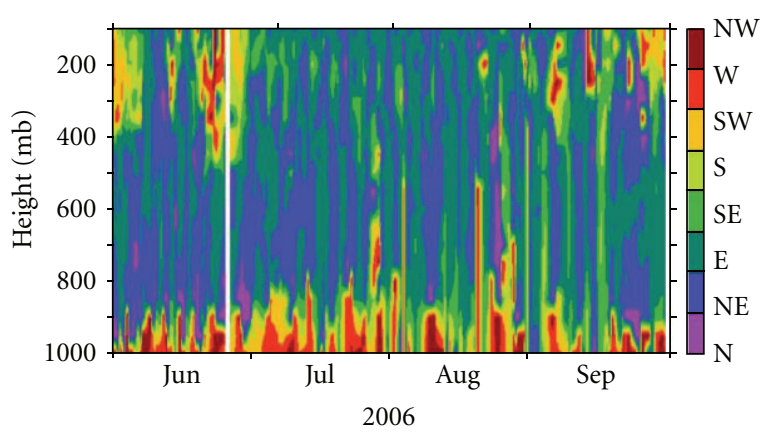

Time evolution of the vertical profile: the mean daily wind direction during JJAS at Dakar in 2006

(a) Dakar

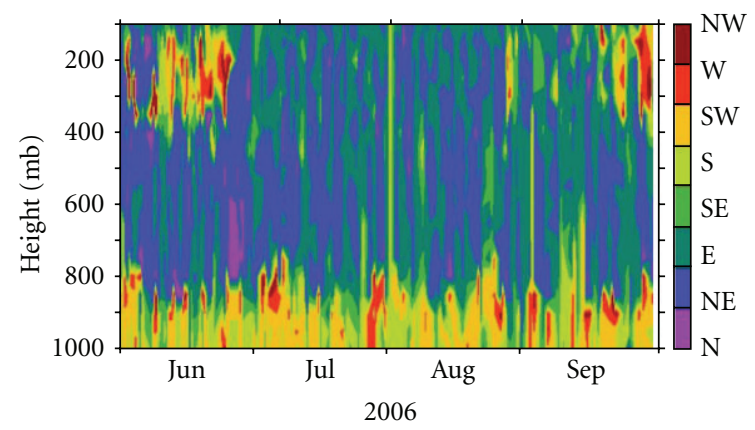

Time evolution of the vertical profile: the mean daily wind direction during JJAS at Niamey in 2006

(b) Niamey

FIGURE 8: Daily wind direction profiles in Dakar and Niamey at 0000 UTC and 1200 UTC of JJAS 2006.

Figure 6(b) shows that at the low levels, the dew point temperatures $\mathrm{Td}$ are higher in Niamey, between $20^{\circ} \mathrm{C}$ and $30^{\circ} \mathrm{C}$, with frequent temporal discontinuities. However, the values of $\mathrm{Td}$ between $10^{\circ} \mathrm{C}$ and $20^{\circ} \mathrm{C}$ are observed consistently in the low levels throughout the JJAS period; low values of $\mathrm{Td}$ occur only in the mid levels. This situation suggests a dry air intrusions at the low levels at Niamey (Figure 6(b)).

The profiles of the dew point temperature patterns at the low levels in Dakar and Niamey are quite similar to those of moisture. The presence at the low levels of dry air at Dakar site in early season can be particularly noted.

3.3. Profiles of the Wind Speed at Coastal (Dakar) and Continental (Niamey) Sites in JJAS 2006. Figure 7(a) shows that early in the season (June), the African Easterly Jet (AEJ) is weaker at the mid levels at Dakar site. The AEJ starts increasing from mid-June with intensity between 15 and $25 \mathrm{~m} \cdot \mathrm{s}^{-1}$ until the end of the season; its maximum intensity is observed in August. Note also that the AEJ can weaken or disappear sometimes during the season. The Tropical Easterly Jet (TEJ) appears at the beginning of July and continues until August with an intensity ranging from 10 to $25 \mathrm{~m} \cdot \mathrm{s}^{-1}$.
Figure 7(b) shows, in contrast to Dakar, that the AEJ at Niamey is intense with speeds up to $25 \mathrm{~m} \cdot \mathrm{s}^{-1}$ in June. It presents discontinuities until the end of the season. The TEJ, with an intensity ranging from $10 \mathrm{~m} \cdot \mathrm{s}^{-1}$ and $25 \mathrm{~m} \cdot \mathrm{s}^{-1}$, is visible only from July and disappears in late August.

The AEJ is more regular and stronger in Dakar than in Niamey, and the TEJ is stronger in Niamey than in Dakar. The AEJ is established earlier in Niamey than in Dakar. The TEJ is much more intense in Niamey.

3.4. Profiles of Wind Direction at Coast (Dakar) and Continental (Niamey) Sites in JJAS 2006. Figure 8(a) shows that at low levels, wind direction varies at Dakar site from Northwest (Harmattan), Southeast and Southwest during JJAS period. But the prevailing winds are South-West (monsoon) and begin early in the season (June). We observe Southwest winds at up levels $(200 \mathrm{hPa})$ at the beginning and the end of the season.

Figure 8(b) shows that in Niamey at the low levels, wind direction varies from southwest (Monsoon), southsouthwest. The prevailing wind direction is Southwest (monsoon) with fluctuations in other directions. At up levels in Niamey, at the beginning and end of the season, we observe sometimes southwest and south winds. The dominant wind 


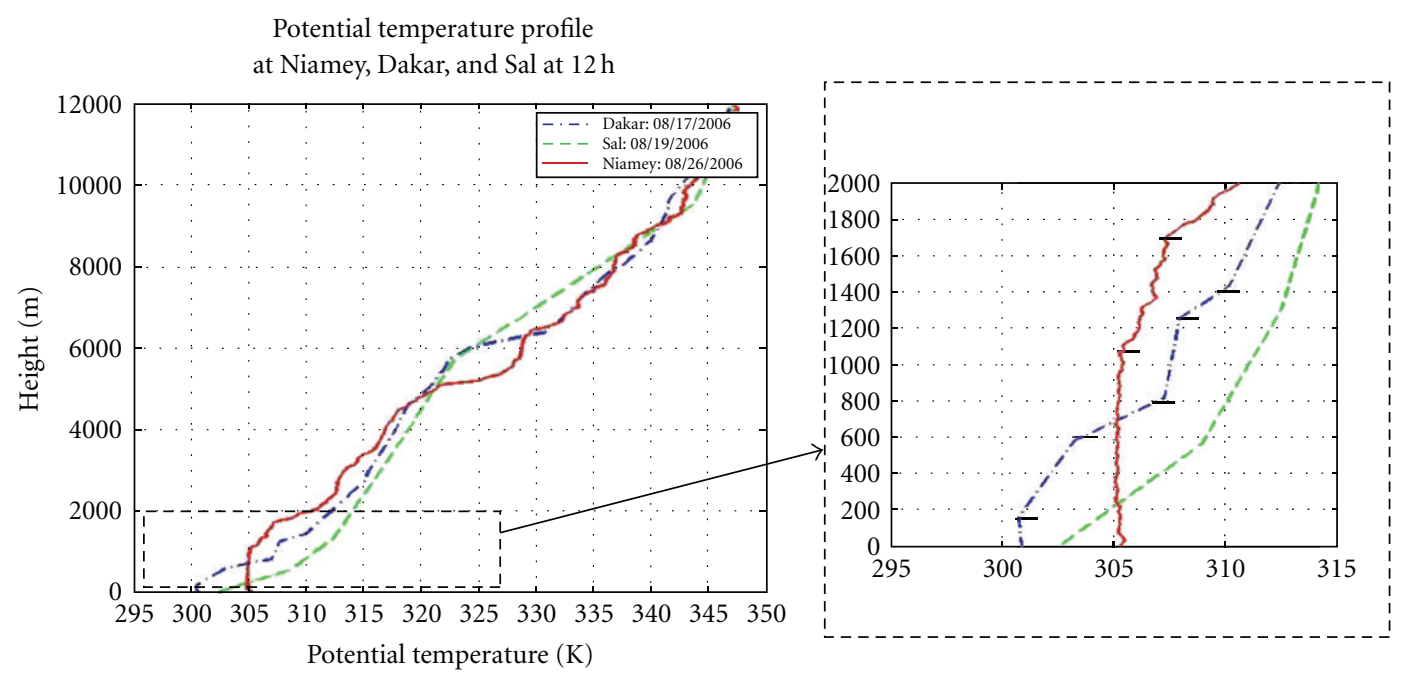

FIgure 9: Profiles of potential temperature $\theta$ at 1200 UTC of 08/17/06 in Dakar (blue), of 08/26/06 in Niamey (red), and of 08/19/06 in Sal (green).

directions in Dakar and Niamey are Southwest at low levels and indicate the presence of the monsoon. At the up levels $(200 \mathrm{hPa})$ at the beginning and the end of the season, we have the same dominant directions from east in Dakar and in Niamey.

3.5. Comparison of Atmospheric Boundary Layer in Niamey, Dakar, and Sal. We compare the structures of inland, coastal, and marine boundary layers in the lower troposphere in the range 0 to 2000 meters using their characteristic parameters, their static stability stratification and thermal properties, and moisture content. To do this, we use the sounding data at 1200 UTC and 0000 UTC of the case studies presented in Section 2.

\subsubsection{Comparison of Boundary Layers at 1200 UTC}

(1) ABL Structure. Table 2 gives the values of characteristic parameters of the boundary layer obtained from the profiles of potential temperature $\theta$ deduced from 1200 UTC case studies soundings (Figure 9). We observe the deepest mixing layer of $1000 \mathrm{~m}$ thick at inland (Niamey), while at the coast (Dakar), the mixing layer is shallow, and at the sea (Sal), it does not exist. The capping inversion is thick $(600 \mathrm{~m})$ in Niamey (red), but its temperature magnitude is very small $(1 \mathrm{~K})$. The ground-based inversion in Sal (green) is thick enough $(550 \mathrm{~m})$ with a strong temperature magnitude $(6 \mathrm{~K})$. We observe that the inversion amplitude is greatest in Sal and lowest in Niamey.

(2) Static Stability. We indicate in Table 3 the static stability stratification of the boundary layers for inland, coastal, and marine profiles deduced from equivalent potential temperature $\theta_{e}$ (Figure 10). In Niamey, there is a thick unstable layer from 0 to $1100 \mathrm{~m}$ topped by a neutral layer up to $2000 \mathrm{~m}$. This unstable layer thickness coincides with the mixing layer (Table 2 ).
TABLE 2: Characteristic parameters of continental (Niamey), coastal (Dakar), and marine (Sal) boundary layers at 1200 UTC for respective case studies.

\begin{tabular}{lccc}
\hline Variable & $\begin{array}{c}\text { Niamey } \\
1200 \text { UTC }\end{array}$ & $\begin{array}{c}\text { Dakar } \\
1200 \text { UTC }\end{array}$ & $\begin{array}{c}\text { Sal } \\
1200 \mathrm{UTC}\end{array}$ \\
\hline$h_{0}(\mathrm{~m})$ & 1100 & 200 & 0 \\
$h_{s}(\mathrm{~m})$ & 0 & 0 & 0 \\
$h_{2}(\mathrm{~m})$ & 1700 & 600 & 550 \\
$\Delta h(\mathrm{~m})$ & 600 & 200 & 550 \\
$\Delta \theta(\mathrm{K})$ & 1 & 3 & 6 \\
$\theta_{m}(\mathrm{~K})$ & 306 & 301 & - \\
$\theta_{00}(\mathrm{~K})$ & 306,5 & 302 & 307,5 \\
$\gamma\left(\mathrm{K} \cdot \mathrm{km}^{-1}\right)$ & 8,5 & 22,5 & 8,1 \\
\hline
\end{tabular}

In Dakar, there is a complex stratification with an unstable layer surmounted by a neutral layer and a double layer alternating unstable and stable. The unstable first layer overlaps the mixing layer thickness.

At Sal, the boundary layer has a stratification characterized by a thick layer of ground-based stability, which explains the absence of the mixing layer. This stable layer is surmounted by a thick layer of instability from 600 to $2000 \mathrm{~m}$.

(3) Thermal Properties. Figure 10 also indicates that the air in Sal (green) is much warmer than in Dakar (blue) and Niamey (red) from $200 \mathrm{~m}$. Between 0 and $200 \mathrm{~m}$, the air in Niamey is warmer than in other sites. It is the coolest above $700 \mathrm{~m}$. Below $700 \mathrm{~m}$, the air of Dakar is the coolest of all. The warmer air in Sal in the layer $200-2000 \mathrm{~m}$ is due to the existence of the Saharan Air Layer (SAL). Warm air in Niamey in the range $0-200 \mathrm{~m}$ is an expected result due to the stronger daytime heating over a land surface. The existence of a warmer air in Dakar above $700 \mathrm{~m}$ may be explained by the influence of Saharan Air Layer in Dakar. 
TABLE 3: Static stability stratification of ABL determined from equivalent potential temperature $\theta_{e}$ at 1200 UTC for case studies.

\begin{tabular}{|c|c|c|c|}
\hline Stations & Study case & Inversion of $\theta_{e}$ & Characterization \\
\hline \multirow{3}{*}{ Niamey (red) } & \multirow{3}{*}{$08 / 26 / 06$ at 1200 UTC } & 0-1000 m & Unstable layer \\
\hline & & $1000-1700 \mathrm{~m}$ & Neutral layer \\
\hline & & $1700-2000 \mathrm{~m}$ & Stable layer \\
\hline \multirow{6}{*}{ Dakar (blue) } & \multirow{6}{*}{$08 / 17 / 06$ at $1200 \mathrm{UTC}$} & $0-200 \mathrm{~m}$ & Unstable Layer \\
\hline & & $200-600 \mathrm{~m}$ & Neutral layer \\
\hline & & $600-800 \mathrm{~m}$ & Stable layer \\
\hline & & $800-1300 \mathrm{~m}$ & Unstable layer \\
\hline & & $1300-1400 \mathrm{~m}$ & Unstable layer \\
\hline & & $1400-2000 \mathrm{~m}$ & Unstable layer \\
\hline \multirow{2}{*}{ Sal (green) } & \multirow{2}{*}{$08 / 19 / 06$ at 1200 UTC } & $0-600 \mathrm{~m}$ & Stable layer \\
\hline & & $600-2000 \mathrm{~m}$ & Unstable layer \\
\hline
\end{tabular}

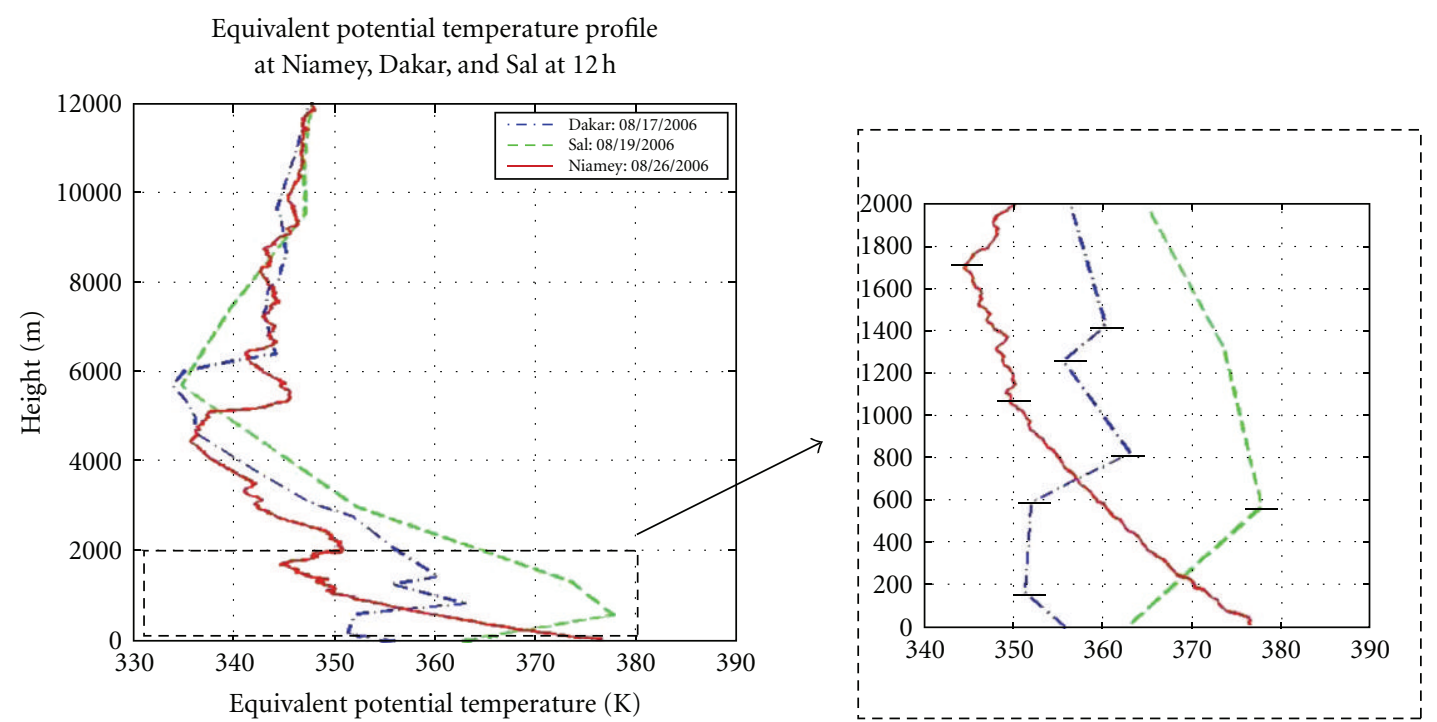

Figure 10: Equivalent potential temperature $\left(\theta_{e}\right)$ profiles at 1200 UTC of 08/17/06 in Dakar (blue), 08/26/06 in Niamey (red), and 08/19/06 in Sal (green).

(4) Moisture Properties. Figure 11 shows profiles of mixing ratio. The values of the mixing ratio $r$ of continental (Niamey), coastal (Dakar), and marine (Sal) sites are, respectively, $12,16.5$, and $15.5 \mathrm{~g} / \mathrm{kg}$ at the ground level and decreases linearly with height. Note that the boundary layer in Niamey (red) is significantly wetter than in Dakar (blue) and Sal (green) between $500-1800 \mathrm{~m}$, but it is drier between $0-500 \mathrm{~m}$. The boundary layer of Dakar (blue) is more humid than in Sal (green) and Niamey (red) significantly between $0-500 \mathrm{~m}$. Then, it is drier between 600-2000 $\mathrm{m}$ in Dakar. The boundary layer of Sal (green) is more humid than in Dakar (blue) and Niamey (red) between $600-1800 \mathrm{~m}$. These moisture properties differences can be explained by the fact that during the JJAS period, the Dakar and Sal sites were influenced by the Saharan Air Layer (SAL), which is characterized by drier air than in Niamey.

\subsubsection{Comparison of Boundary Layers at 0000 UTC}

(1) ABL Structure. Table 4 gives the values of characteristic parameters obtained from the profiles of potential temperature $\theta$ (figure not shown) deduced from 0000 UTC case studies soundings.

Here the thickest mixing layer $(400 \mathrm{~m})$ is observed at the coast (Dakar), while on the continent (Niamey), the mixing layer is shallow and does not exist at all on the sea (Sal). However, there is a residual mixing layer between $300-1000 \mathrm{~m}$ in Niamey. The capping inversion is very thick $(800 \mathrm{~m})$ in Dakar, and its thermal amplitude is strong enough $(4 \mathrm{~K})$. The ground-based inversion in Sal is thick enough $(500 \mathrm{~m})$ with a low temperature range $(2 \mathrm{~K})$. It is found that the amplitude of the inversion is lower in Sal.

(2) Static Stability. Table 5 shows the stratification of the static stability of boundary layers for inland, coastal, and 


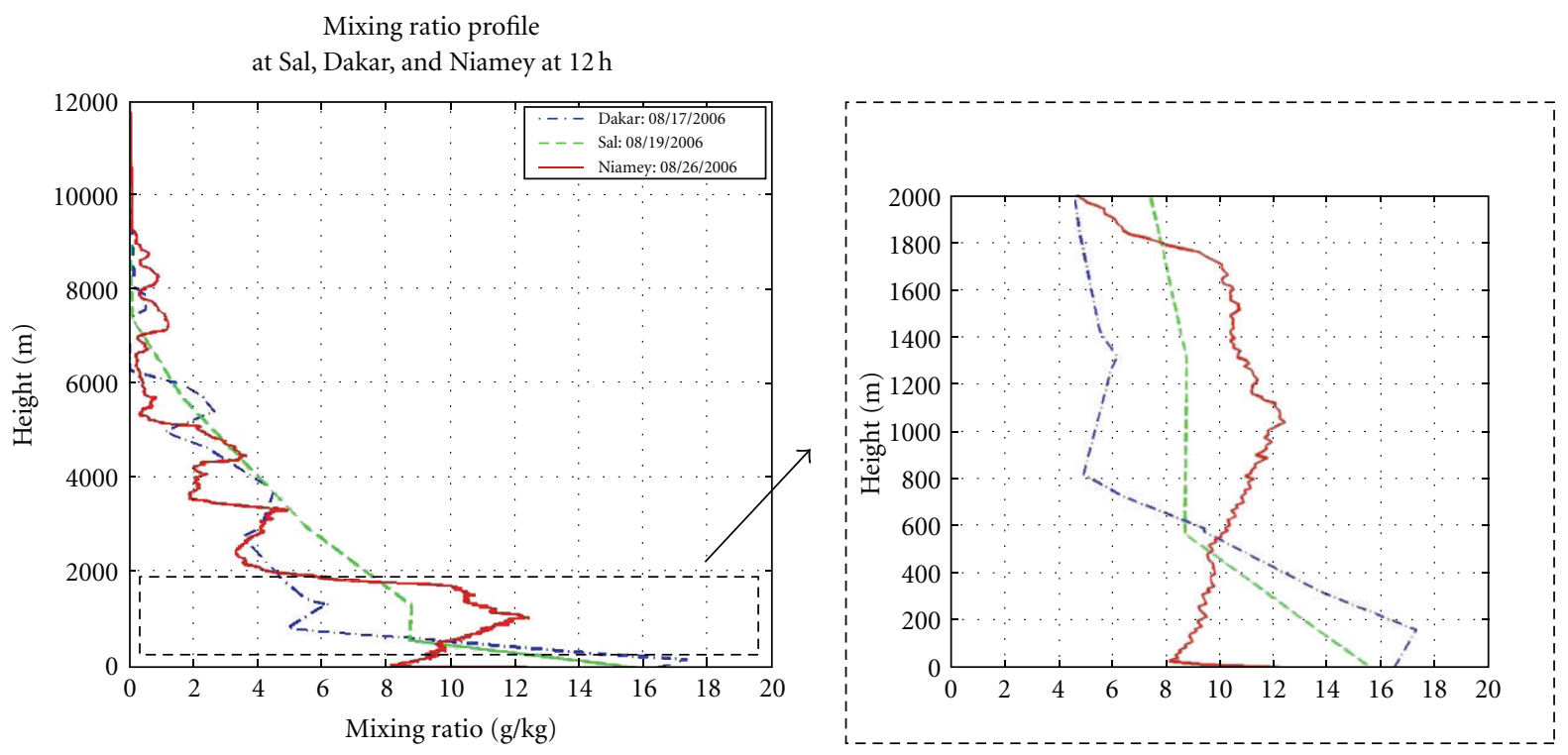

Figure 11: Mixing ratio $(r)$ profiles at 1200 UTC of 08/26/06 in Niamey (red), at 08/17/06 in Dakar (blue), and at 08/19/06 in Sal (green).

TABLE 4: Characteristic parameters of the continental boundary layer (Niamey), coastal (Dakar), and marine (Sal) at 0000 UTC for case study.

\begin{tabular}{lccc}
\hline Parameters & $\begin{array}{c}\text { Niamey } \\
0000 \text { UTC }\end{array}$ & $\begin{array}{c}\text { Dakar } \\
\text { 0000 UTC }\end{array}$ & $\begin{array}{c}\text { Sal } \\
\text { 0000 UTC }\end{array}$ \\
\hline$h_{0}(\mathrm{~m})$ & 180 & 400 & 0 \\
$h_{s}(\mathrm{~m})$ & 0 & 0 & 0 \\
$h_{2}(\mathrm{~m})$ & 310 & 800 & 500 \\
$\Delta h(\mathrm{~m})$ & 120 & 200 & 500 \\
$\Delta \theta(\mathrm{K})$ & 4 & 4 & 2 \\
$\theta_{m}(\mathrm{~K})$ & 302 & 302 & - \\
$\theta_{00}(\mathrm{~K})$ & 303 & 307 & 299 \\
$\gamma\left(\mathrm{K} \cdot \mathrm{km}^{-1}\right)$ & 8,7 & 47,8 & 8 \\
$h_{0}^{\prime}(\mathrm{m})$ & 1000 & & \\
$h_{s}^{\prime}(\mathrm{m})$ & 300 & & \\
$h_{2}^{\prime}(\mathrm{m})$ & 1050 & & \\
$\Delta h^{\prime}(\mathrm{m})$ & 50 & & \\
$\Delta \theta^{\prime}(\mathrm{K})$ & 1 & & \\
$\theta_{m}^{\prime}(\mathrm{K})$ & 303 & & \\
\hline
\end{tabular}

The "prime" denotes the same parameter as in the first list when there is a residual mixed layer.

marine sites derived from profiles of equivalent potential temperature $\theta_{e}$ (figure not shown).

In Niamey, there is a very thin unstable layer from 0 to $180 \mathrm{~m}$ surmounted by a stable layer up to $300 \mathrm{~m}$. Then there is a thick unstable layer from 300 to $1000 \mathrm{~m}$. Then there is a neutral layer from 1000 to $1800 \mathrm{~m}$. Beyond and up to $2000 \mathrm{~m}$, there is a stable layer. The unstable layer 300 $1000 \mathrm{~m}$ coincides in thickness with the residual mixing layer (Figure 12(b)).

In Dakar, there is a complex stratification with a thin unstable layer surmounted by double alternating unstable and stable layers. The unstable first layer in Dakar is the mixing layer.

In Sal, the boundary layer is characterized by a layer of instability $0-500 \mathrm{~m}$ capped by a thick layer of stability from 500 to $1200 \mathrm{~m}$. Then there is an alternation of a thin unstable layer (1200-1400 m) and a stable layer (1400-2000 m). The ground-based thick layer of instability at Sal is a mixing layer not detectable on the profile of potential temperature $\theta$.

(3) Thermal and Moisture Properties. At night, the warmest air in Dakar is aloft from 400 to $2000 \mathrm{~m}$. Below $400 \mathrm{~m}$, the warmest air is in Niamey. From the surface to about $800 \mathrm{~m}$, the coolest air is found in Sal. Above $800 \mathrm{~m}$, the coolest air is observed in Niamey (figure not shown).

This configuration of the temperature profiles during the night is a bit unexpected. The warmer air in Dakar could be explained by the influence of the Saharan air layer, which would not have influenced the site of Sal during the night (Figure 2).

Note that the boundary layer in Niamey is significantly moister than in Dakar and Sal from the surface to $2000 \mathrm{~m}$ (figure not shown). The boundary layer of Dakar is more humid than Sal up to $400 \mathrm{~m}$, and moisture in Dakar and Sal decreases above $400 \mathrm{~m}$. In Dakar, there was a significant dryness above $400 \mathrm{~m}$, confirming the influence of SAL (Sahara Air Layer).

3.6. Evolution of the Daytime Boundary Layer. Let us compare, between 1200 UTC and 0000 UTC, the structures and thermodynamic properties of boundary layers for case studies. Remember that 0000 UTC sounding data in question is that of the previous day or the next day at Niamey and Dakar site. But at Sal site, because of the nonexisting data, we took the night sounding data closest in time, which happens 4 days after. This causes that the evolution of the boundary layer is not of diurnal scale at Sal but the comparison is made 
TABLE 5: Static stability stratification of ABL determined from the equivalent potential temperature $\theta_{e}$ at 0000 UTC for case studies.

\begin{tabular}{|c|c|c|c|}
\hline Stations & Study case & Stratification of $\theta_{e}$ & characterization \\
\hline \multirow{4}{*}{ Continental (Niamey) } & \multirow{4}{*}{$08 / 25 / 06$ at 0000 UTC } & $0-180 \mathrm{~m}$ & unstable layer \\
\hline & & $180-300 \mathrm{~m}$ & stable layer \\
\hline & & $300-1000 \mathrm{~m}$ & unstable layer \\
\hline & & $1000-1800 \mathrm{~m}$ & neutral layer \\
\hline \multirow{5}{*}{ Coastal (Dakar) } & \multirow{5}{*}{ 08/18/06 at $0000 \mathrm{UTC}$} & 0-380 m & unstable layer \\
\hline & & $380-580 \mathrm{~m}$ & stable layer \\
\hline & & $580-840 \mathrm{~m}$ & unstable layer \\
\hline & & $840-1400 \mathrm{~m}$ & stable layer \\
\hline & & $1400-2000 \mathrm{~m}$ & unstable layer \\
\hline \multirow{4}{*}{ Marine (Sal) } & \multirow{4}{*}{ 08/23/06 at $0000 \mathrm{UTC}$} & $0-500 \mathrm{~m}$ & unstable layer \\
\hline & & $500-1200 \mathrm{~m}$ & stable layer \\
\hline & & $1200-1400 \mathrm{~m}$ & unstable layer \\
\hline & & $1400-2000 \mathrm{~m}$ & stable layer \\
\hline
\end{tabular}

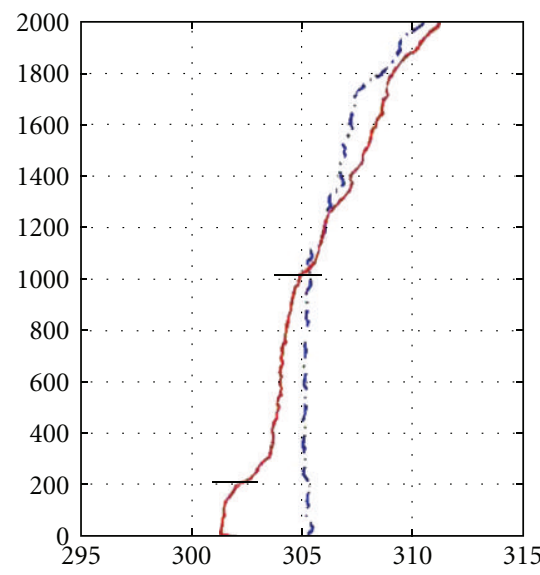

(a)

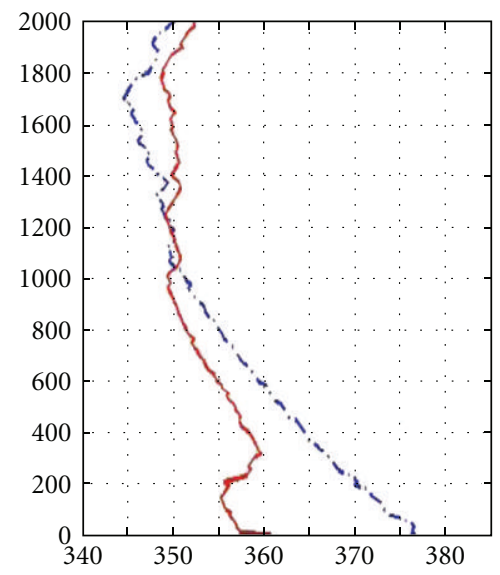

(b)

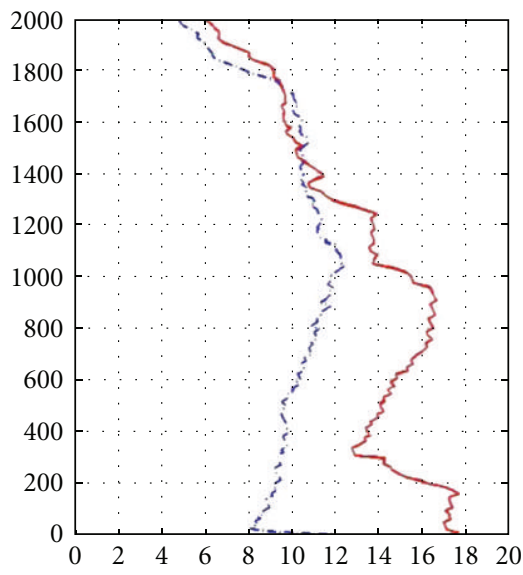

(c)

FIGURE 12: Potential temperature $\theta$ (a), equivalent potential temperature $\theta_{e}$ (b), and mixing ratio $r$ (c) profiles 08/26/06 at 0000 UTC (red) and 1200 UTC (blue) in Niamey.

between a daytime boundary layer and nocturnal boundary layer.

3.6.1. Change in the ABL Structure. A joint reading of Tables 2 and 4 shows that the height of the Niamey mixing layer decreased significantly from 1600 to $120 \mathrm{~m}$ from day to night, and also this is shown in Figure 8(a). Meanwhile, the height of the capping inversion height fell from 1700 to $300 \mathrm{~m}$. The thickness of the inversion layer has also decreased from 600 to $120 \mathrm{~m}$, but its thermal amplitude is increased from 1 to $4 \mathrm{~K}$. Furthermore, it has established a residual mixing layer whose thickness is considerable. In fact, the daytime mixing layer ground-based, was divided into two mixing layers with a mixing layer at the bottom very shallow $0-180 \mathrm{~m}$ and a residual mixing layer depth of $300-1000 \mathrm{~m}$. Between the two layers is a layer corresponding to the stable nocturnal inversion.

In Dakar, the height of the mixing layer increased from day to night; from 200 to $400 \mathrm{~m}$ along the height of the inversion layer is increased from 600 to $800 \mathrm{~m}$ at night
(Figure 10(a)). The thickness of the inversion layer remained unchanged but its thermal amplitude was increased by 3 to $4 \mathrm{~K}$ from daytime to nighttime. In short, the diurnal evolution has resulted in an increase in thickness of the mixing layer due to turbulence associated to nonthermal phenomena surely mesoscale or large-scale one.

In Sal, the nocturnal boundary layer structure is similar to that of the daytime: with the absence of a mixing layer and the existence of a thick layer of ground-based inversion, the height has increased slightly from 500 to $550 \mathrm{~m}$ from night to day (Figure 11(a)).

3.6.2. Diurnal Evolution of Static Stability. In Niamey, there is the establishment of a stable layer at night between 180 and $300 \mathrm{~m}$ and a neutral layer between 1000 and 1800 (Figure 12(b)). Thus the nocturnal boundary layer comprises two unstable layers separated by a stable layer corresponding to the component called the stable boundary layer (SBL) and a neutral layer between 1000-1800 m. The diurnal evolution of the static stability of the boundary layer 


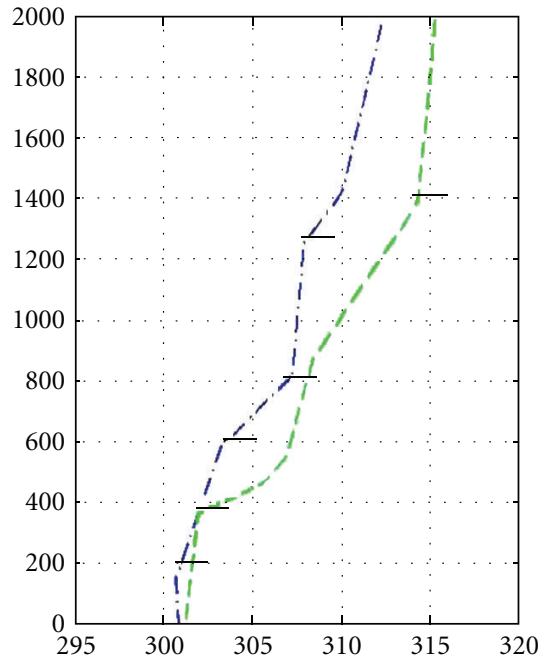

(a)

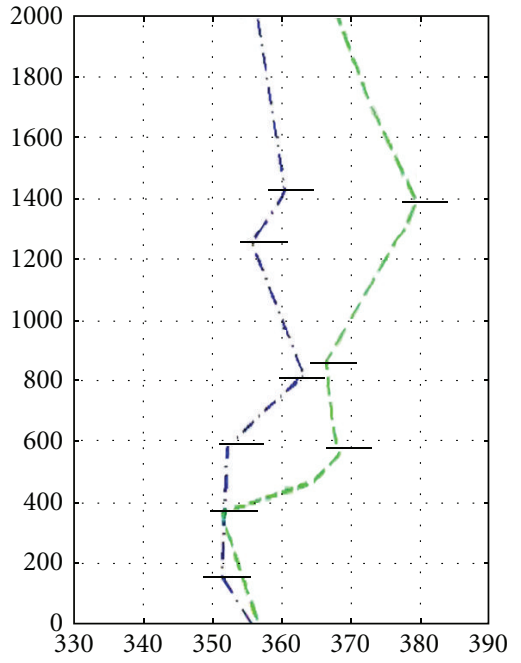

(b)

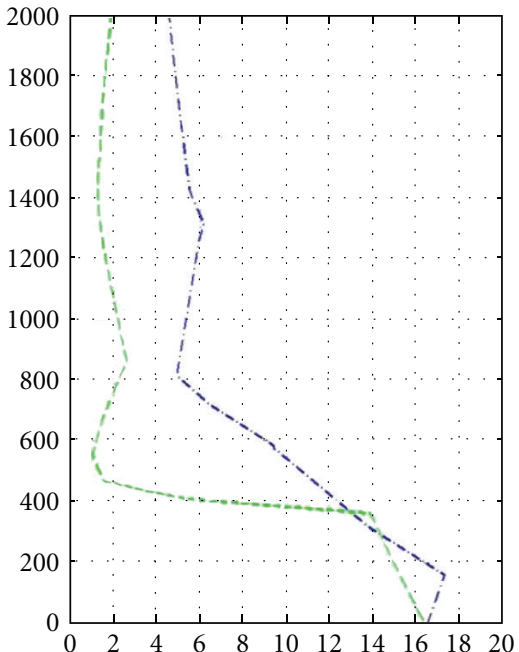

(c)

Figure 13: Potential temperature $\theta$ (a), equivalent potential temperature $\theta_{e}(\mathrm{~b})$, and mixing ratio $r$ profiles (c) of $08 / 17 / 06$ at 1200 UTC (blue) and 08/18/06 at 0000 UTC (green) in Dakar.

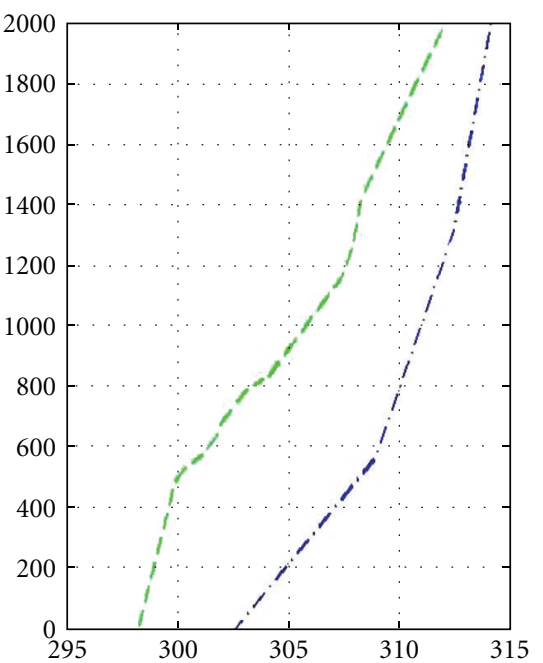

(a)

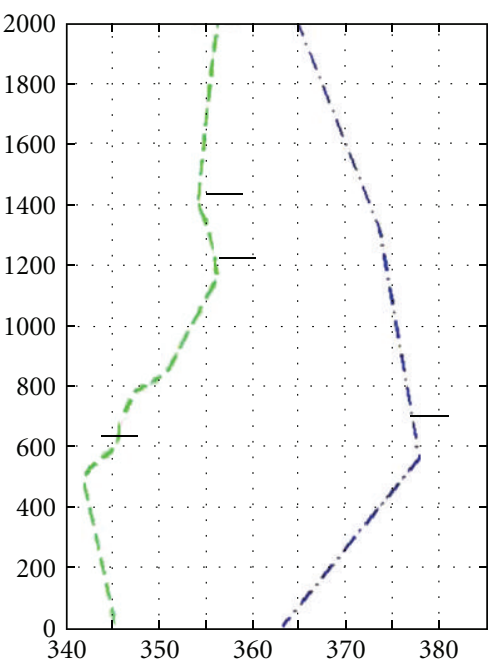

(b)

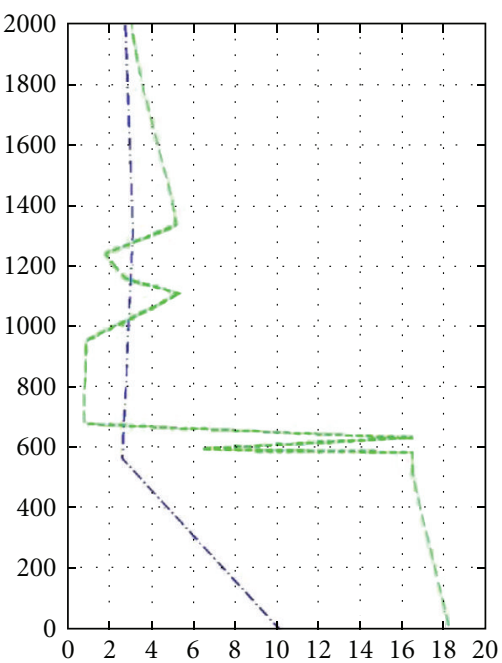

(c)

Figure 14: Potential temperature $\theta$ (a), equivalent potential temperature $\theta_{e}$ (b), and mixing ratio $r$ (c) profiles of 08/19/06 at 1200 UTC (blue) and 08/23/06 at 0000 UTC (green) in Sal.

in Niamey has led to a stabilization of a portion of the lower half of the daytime unstable layer and a moving to the neutral state of the upper half. Overall, the instability of the daytime boundary layer was maintained during the whole night but was somewhat weakened in its top and bottom.

In Dakar, the diurnal evolution of the static stratification is characterized by the destruction during the night of the neutral layer whose lower part became unstable and whose upper part was stabilized. Also the stable layer 600$800 \mathrm{~m}$ during daytime became unstable (Figure 13(b)). And conversely, the unstable layer $800-1300 \mathrm{~m}$ stabilized during the nighttime between $850-1400 \mathrm{~m}$. The unstable layer $1400-$ $2000 \mathrm{~m}$ kept the same static state during nighttime. The thickness of the unstable layer corresponding to groundbased mixing layer increased from $200 \mathrm{~m}$ to $400 \mathrm{~m}$ from daytime to nighttime (Figure 13(b)).

In Sal, the mixing ratio profiles indicate that low levels of humidity are almost between $0-300 \mathrm{~m}$ and a slight moistening during nighttime 300 to $400 \mathrm{~m}$. And a nocturnal drying between 400 and $2000 \mathrm{~m}$ is observed (Figure 13(c)).

In Sal, the instability of the layer $0-500 \mathrm{~m}$ at nighttime has replaced the stable layer from 0 to $600 \mathrm{~m}$ observed in daytime (Figure 14(a)). Thick and unstable 600-2000 m layer, which is stabilized during daytime, except for a narrow unstable layer $1200-1400 \mathrm{~m}$, was stable at the nighttime (Figure 14(b)). Overall, the static stratification is modified 
at night with the establishment of instability in low levels between $0-500 \mathrm{~m}$ and a stabilization of the upper troposphere.

3.6.3. Diurnal Evolution of Thermal and Moisture Properties. In Niamey (Figure 12(c)), there is a nighttime cooling of the boundary layer between $0-1500 \mathrm{~m}$, and it is greater in the mixing layer (1500-1700 m). Then, during the daytime, air in the mixing layer is dried between 0 and $1500 \mathrm{~m}$ and 1800 $2000 \mathrm{~m}$ (Figure 12(c)).

The humidity remained unchanged in the boundary layer between 0-2000 $\mathrm{m}$ in Niamey, but there is a slight increase between 400-2000 m. during nighttime. A nocturnal slight drying is confined in the layer $0-200 \mathrm{~m}$ corresponding to the lower mixing layer (Figure 12(a)). Due to the lack of vertical turbulent moving, the air in the stable layer 200$400 \mathrm{~m}$ retained the same level of humidity during daytime as well as nighttime.

In Dakar, a nighttime warming occurs over the entire troposphere (Figure 13(b)) and is low between 0 to $400 \mathrm{~m}$ and becomes more considerable with height and has a maximum between 800 and $2000 \mathrm{~m}$. Humidity profiles are identical in between $0-400 \mathrm{~m}$. Between $400-2000 \mathrm{~m}$, the nocturnal air became drier with a maximum drying at about $600 \mathrm{~m}$.

In Sal, the lower troposphere has cooled a lot during the nighttime between $0-2000 \mathrm{~m}$ with a maximum difference at about $600 \mathrm{~m}$ (Figure 14(b)). Also, the mixing ratio profiles indicate that there are nighttime drying between $0-700 \mathrm{~m}$ and a slight moistening between $700-1000 \mathrm{~m}$ and 13002000 m (Figure 14(c)).

\section{Conclusion}

The profiles of relative humidity during JJAS 2006 indicate a higher humidification of Dakar in the month of June and later in Niamey. There is a boundary layer with higher moisture levels in Dakar and Niamey especially in the season core (July and August). However, there are dry intrusions in the low levels at the beginning and end of the season in Dakar that do not exist in Niamey.

The profiles of wind speed show that the African Easterly Jet (AEJ) and the Tropical Easterly Jet (TEJ) are observed at both sites, but the AEJ is stronger and more regular in Dakar than in Niamey. TEJ is stronger in Niamey than in Dakar.

The profile analysis of some thermodynamic parameters deduced from sounding data of our case studies selected by the criterion of the CAPE monthly maximum shows the following main findings.

The profile of equivalent potential temperature $\theta_{e}$ also determines the static stability of each of the different sublayers of the boundary layer and defines their respective thicknesses. The mixing layer always corresponds to an unstable layer and the inversion layer to a stable layer.

The boundary layer comparison showed that the mixing layer on the continent during daytime can reach a height $h_{1}$ greater than $1100 \mathrm{~m}$, and the inversion layer height $h_{2}$ can exceed $1700 \mathrm{~m}$. Therefore, the maximum thickness of the boundary layer is observed on the continent during daytime, while at nighttime the marine boundary layer is the thickest.

The diurnal evolution determined from our case study shows that the thickness of the mixing layer decreases during nighttime over the continent but increases at the coast and at sea. During nighttime, at the continental site of Niamey, we observe a division of the mixing layer into two parts; the upper mixing layer is the residual layer.

The continental boundary layer is more unstable at daytime while at nighttime it is the marine boundary layer that is more unstable than the coastal and continental ones.

The coastal mixing layer (Dakar) is significantly wetter than the continental (Niamey) and marine (Sal) ones. The marine mixing layer (Sal) is significantly wetter than the continental one (Niamey). The nighttime cooling is greater at sea than at the coast and at the continent.

Our future work will focus on the seasonal evolution of the structure and properties of temperature and humidity of the atmospheric boundary layer, respectively, at the inland, coastal, and marine sites to validate the preliminary findings of the present study which focused on a few case studies.

\section{Acknowledgments}

The authors present their sincere thanks to the RIPIESCA project (Interdisciplinary and Participatory Research on the Interactions between Ecosystems, Climate and Societies in West Africa), the Institute of Development Research (IDR), and the University Agency of the Francophony (UAF), which has enabled this work to be carried out.

\section{References}

[1] W. Prandtl and F. Lustig, "Ueber complexe verbindungen des fünfwerthigen vanadins mit vierwerthigen elementen," Berichte der Deutschen Chemischen Gesellschaft, vol. 38, pp. 1305-1310, 1905.

[2] J. Turner, Buoyancy Effects and Fluids, Cambridge University, 1973.

[3] A. S. Monin, "The atmospheric boundary layer," Annual Review of Fluid Mechanics, vol. 2, pp. 225-250, 1970.

[4] O. Zeman, "Progress in the modeling of planetary boundary layers," Annual Review of Fluid Mechanics, vol. 13, pp. 253272, 1981.

[5] B. Cushman-Roisin and J. M. Beckers, Introduction to Geophysical Fluid Dynamics: Physical and Numerical Aspects, Accademic Press, 2009.

[6] C. Renaudie, Etude et validation des couches limites atmosphériques et océaniques locales, Ph.D. thesis, université de Toulouse III-Paul Sabatier, 2009.

[7] A. K. Betts, J. H. Ball, A. C. M. Beljaars, M. J. Miller, and P. A. Viterbo, "The land surface-atmosphere interaction: a review based on observational and global modeling perspectives," Journal of Geophysical Research D, vol. 101, no. 3, pp. 72097225, 1996.

[8] R. H. Johnson, "Large-scale effects of deep convection on the GATE tropical boundary layer," Journal of the Atmospheric Sciences, vol. 38, no. 11, pp. 2399-2413, 1981. 
[9] M. Lothon, F. Couvreux, S. Donier et al., "Impact of coherent eddies on airborne measurements of vertical turbulent fluxes," Boundary-Layer Meteorology, vol. 124, no. 3, pp. 425-447, 2007.

[10] F. Saïd, G. Canut, P. Durand, F. Lohou, and M. Lothon, "Seasonal evolution of boundary-layer turbulence measured by aircraft during the AMMA 2006 special observation period," Quarterly Journal of the Royal Meteorological Society, vol. 136, no. 1, pp. 47-65, 2010.

[11] G. Canut, M. Lothon, F. Saïd, and F. Lohou, "Observation of entrainment at the interface between monsoon flow and the Saharan air layer," Quarterly Journal of the Royal Meteorological Society, vol. 136, no. 1, pp. 34-46, 2010.

[12] J. Redelsperger, C. Thorncroft, A. Diedhiou, T. Lebel, D. J. Parker, and J. Polcher, "African monsoon multidisciplinary analysis: an international research project and field campaign," Bulletin of the American Meteorological Society, vol. 87, no. 12, pp. 1739-1746, 2006.

[13] P. Drobinski, "Dynamique de la couche limite atmosphérique: de la turbulence aux systems de méso-échelle," Synthèse d'activité scientifique proposée pour une thèse d'habilitation à diriger des recherches de l'Université Paris VI, p. 150, 2009.

[14] J. M. Prospero and T. N. Carlson, "Vertical and areal distribution of. Saharan dust over the westem equatorial north atlantic ocean," Journal of Geophysical Research, vol. 77, no. 27, pp. 5255-5265, 1972.

[15] J. W. Deardoff, "Prediction of convective mixed-layer entrainment for realistic capping inversion structure," Journal of Atmospheric Sciences, pp. 558-567, 1978.

[16] P. Seibert, F. Beyrich, S. E. Gryning, S. Joffre, A. Rasmussen, and P. Tercier, "Review and intercomparison of operational methods for the determination of the mixing height," Atmospheric Environment, vol. 34, no. 7, pp. 1001-1027, 2000.

[17] S. K. Nair, T. J. Anurose, D. Bala Subrahamanyam et al., "Characterization of the vertical structure of coastal atmospheric boundary layer over thumba $\left(8.5^{\circ} \mathrm{N}, 76.9^{\circ} \mathrm{E}\right)$ during different seasons," Advances in Meteorology, vol. 2011, Article ID ID 390826, 9 pages, 2011.

[18] G. Rampanelli and D. Zardi, "A method to determine the capping inversion of the convective boundary layer," Journal of Applied Meteorology, vol. 43, no. 6, pp. 925-933, 2004.

[19] H. Tennekes, "A model for the dynamics of the inversion above a convective boundary," Journal of Atmospheric Science, vol. 30, no. 4, pp. 558-567, 1973.

[20] A. G. M. Driedonks, "Models and observations of the growth of the atmospheric boundary layer," Boundary-Layer Meteorology, vol. 23, no. 3, pp. 283-306, 1982.

[21] X. Zeng, M. A. Brunke, M. Zhou, C. Fairall, N. A. Bond, and D. H. Lenschow, "Marine atmospheric boundary layer height over the Eastern pacific: data analysis and model evaluation," Journal of Climate, vol. 17, no. 21, pp. 4159-4170, 2004. 

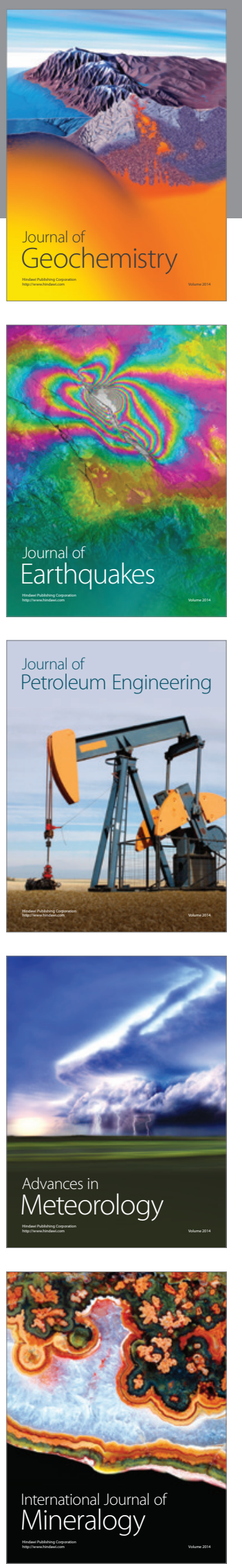
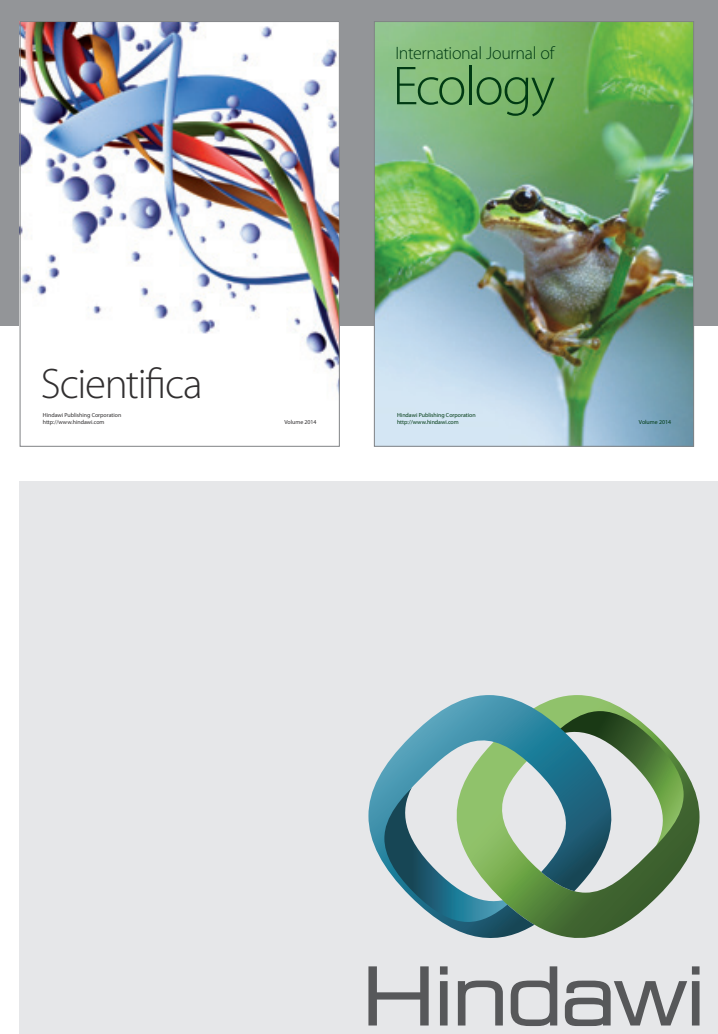

Submit your manuscripts at http://www.hindawi.com
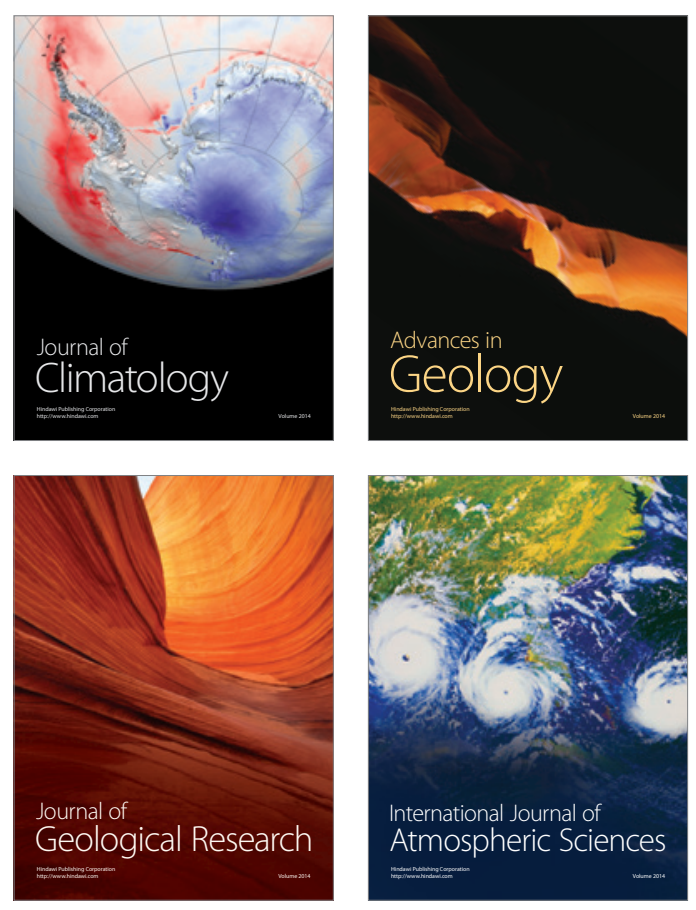
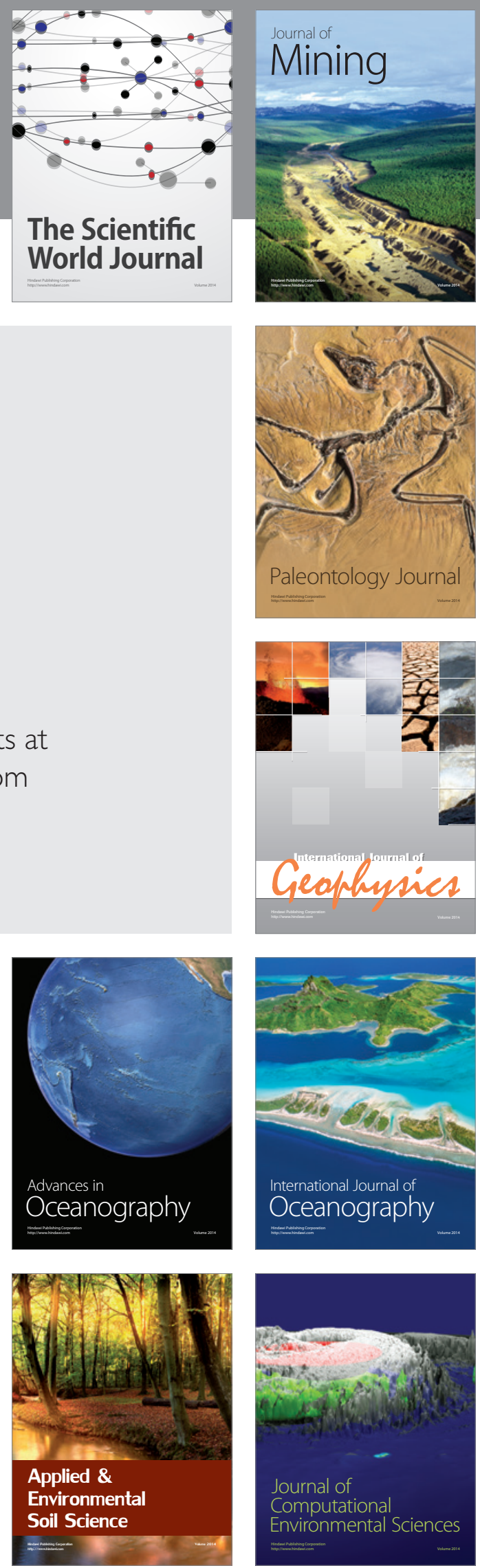